\title{
Hospital admissions in older people with visual impairment in Britain
} Jennifer R Evans*1,2, Liam Smeeth ${ }^{2}$ and Astrid E Fletcher ${ }^{2}$

Address: ${ }^{1}$ International Centre for Eye Health, London School of Hygiene and Tropical Medicine (LSHTM), Keppel Street, London, WC1E 7HT, UK and ${ }^{2}$ Non-Communicable Disease Epidemiology Unit, LSHTM, Keppel Street, London, WC1E 7HT, UK

Email: Jennifer R Evans* - jennifer.evans@lshtm.ac.uk; Liam Smeeth - liam.smeeth@lshtm.ac.uk; Astrid E Fletcher - astrid.fletcher@lshtm.ac.uk

* Corresponding author

Published: II September 2008

BMC Ophthalmology 2008, 8:16 doi:10.1186/147I-2415-8-16

This article is available from: http://www.biomedcentral.com/I47I-24I5/8/16

(c) 2008 Evans et al; licensee BioMed Central Ltd.

This is an Open Access article distributed under the terms of the Creative Commons Attribution License (http://creativecommons.org/licenses/by/2.0), which permits unrestricted use, distribution, and reproduction in any medium, provided the original work is properly cited.
Received: 13 November 2007

Accepted: II September 2008

\begin{abstract}
Background: We aimed to assess the risk of hospital admission associated with visual impairment in a representative sample of older people living in the community in Britain.

Methods: Design: Prospective study of hospital admission in a population-based sample of community dwelling people aged 75 years and above in Britain. Setting: 53 general practices. Participants: 14,394 participants in the MRC Trial of Assessment and Management of Older people in the Community. Main outcome measure: Hospital admission.

Results: Visually impaired older people had 238.7 admissions/1000 person-years compared to 169.7 admissions/ 1000 person-years in people with good vision: age and sex adjusted rate ratio (RR) I.32 (95\% Cl I.I9 to I.47). Adjusting for a wide range of potential explanatory factors largely eliminated this association: RR I.06 $(95 \% \mathrm{Cl} 0.94$ to I.20). However, adjusting for a more limited range of confounding factors, excluding those factors possibly a consequence of reduced vision, left a modest increased risk: RR I.I9 (95\% CI I.06 to I.34).

Conclusion: The association between visual impairment and rate of hospital admission can be attributed to higher levels of co-morbidity and reduced functional ability among people with reduced vision. Visual impairment is likely to be an important contributor to reduced functional ability, but other factors may also be involved.
\end{abstract}

\section{Background}

The prevalence of visual impairment in older people admitted to hospital has been estimated to be as high as $50 \%[1]$. There is limited evidence as to the risk of hospital admission in visually impaired people. One study suggested that there is an increased risk of hospital admission in visually impaired people[2] and one study that visual impairment increases the average length of stay in hospi$\operatorname{tal}[3]$.
The aim of this study was to assess the risk of hospital admission associated with visual impairment in a representative sample of older people living in the community in Britain.

\section{Methods}

The Medical Research Council (MRC) trial of the assessment and management of older people in the community was a large cluster randomised trial in 106 general prac- 
tices from the MRC General Practice Research Framework[4]. The practices in the study were selected to be representative of the mortality (SMR) and Jarman scores of general practices in Britain (England, Wales and Scotland). The aim of the trial was to evaluate the benefit of different methods of assessment and management of older people in the context of the 1990 contract of service which required general practitioners in the UK to offer an annual health check to patients aged 75 years and over. The main results of the trial have been published[5]. The study compared two different types of multidimensional assessment (targeted versus universal) and two different management models (primary care team versus multidisciplinary geriatric evaluation team). Randomisation was at the practice level and stratified by standardised mortality ratio and Jarman score. All patients aged 75 years or over on the general practitioner list were invited to participate in the trial, unless they were in long stay hospital or nursing homes, or were terminally ill.

People in the 53 practices allocated to the "universal" arm of the trial were given a visual acuity test as part of a detailed health assessment by the practice nurse. Visual acuity was measured at 3 metres with a Glasgow Acuity Chart which measures the minimal angle of resolution on a logarithmic scale[6]. Vision was measured both as presenting vision (with spectacle or contact lenses) and also in each eye. People with binocular presenting vision better than $6 / 9$ were defined as "good vision", those with presenting vision less than $6 / 9$ to $6 / 18$ as reduced vision. Visual impairment was defined as presenting binocular acuity of less than 6/18 (logMAR score 0.5 or more). In 49 practices, the cause of visual impairment was assessed by medical record review[7]. Information on hospital admission was collected by trial nurses on an ongoing basis for each patient from the date of the baseline assessment. The baseline assessments were conducted during four years 1995 to 1998; hospital admissions were collected by study nurses for each patient for a 2 -year period from baseline (invitation to assessment) from hospital discharge letters in the patients' GP records. The definition of a hospital admission included an overnight stay. The trial and additional data collection on the cause of visual loss was approved by the relevant local research ethics committees.

All analyses were done using Stata version 10.0 and took into account the cluster design of the study using "svy" commands (Stata Corporation, College Station, Texas 77845, USA). People with an MMSE score of less than 12 were excluded from these analyses because measurement of visual acuity in this group is likely to be inaccurate. The rate ratio of hospital admission associated with visual impairment was estimated using poisson regression. In all analyses the reference group was those with "good vision". The following potential confounding factors and effect modifiers were considered: age, sex, marital status (single/married/widowed), living alone, housing tenure (home owner/not home owner/sheltered accommodation), financial difficulties (difficulties making ends meet and/or managing finances), looked after someone with a serious illness in the last year, death of loved one in last year, social support (no relative/friend to call on and/or no help at night), alcohol consumption (never/ex/current below median/current above median), smoking (never/ ex/current), body mass index (BMI) (quintiles), depression (6 or more on Geriatric Depression Scale), diabetes, hearing impairment (failed whispered voice test), reported major illness (heart attack, stroke, Parkinsons disease, cancer), self-reported health (excellent or very good/good/fair or poor), activities of daily living (ADL) score (unable to do 0-1 ADLs, unable to do 2-4 ADLs, unable to do 5-8 ADLs), falls in last six months (none/ one/two or more), self-reported activity (very or fairly/not very or not at all), cognitive impairment (Mini Mental State Examination (MMSE) score 12-17/18-23/24-30).

Only those variables statistically associated with both hospital admission and visual impairment in this dataset (after controlling for age and sex) were considered as potential explanatory factors in addition to age and sex. These were: marital status, housing tenure, financial difficulties, alcohol consumption, BMI, depression, diabetes, reported major illness, self-reported health, falls, ADL, self-reported activity, MMSE. Because vision impairment may lead to problems with self-reported health, activity, ADLs, falls and depression, and therefore these could be considered to be on the "causal pathway" and thus be explanatory factors rather than confounders, analyses were carried out with and without these variables.

\section{Results}

Response rates and characteristics of non-responders have been published elsewhere[7]. 15,336/21,762(70\%) of eligible people in practices randomised to the universal arm of the MRC trial had a detailed assessment. People taking part were slightly younger and more likely to be men compared to those who did not take part. 14,394/15,336 of people with a detailed assessment were included in the current analyses. Reasons for exclusion were: MMSE $<12$ $(\mathrm{n}=228)$, or no data on vision $(\mathrm{n}=484)$, data on baseline/follow-up not available $(\mathrm{n}=230)$. Table 1 shows the characteristics of the study population.

Table 2 shows the rate of hospital admission in visually impaired people. The rate of hospital admission in visually impaired people was $238.7 / 1000$ person-years compared to $169.7 / 1000$ person-years in people with good vision. The rate ratio adjusted for age and sex was 1.32 (95\% CI 1.19 to 1.47$)$. Adjusting for a wide range of 
Table I: Characteristics of study population

\begin{tabular}{|c|c|c|c|c|c|}
\hline & \multicolumn{3}{|c|}{ Binocular presenting vision with usual glasses } & \multirow[b]{2}{*}{ Missing data } & \multirow[b]{2}{*}{$\begin{array}{c}\text { Association with } \\
\text { visual impairment, } \\
\text { after adjusting } \\
\text { for age and sex* }\end{array}$} \\
\hline & $\begin{array}{c}\text { Good vision } \\
\text { (better than 6/9) } \\
\mathrm{N}=7107\end{array}$ & $\begin{array}{l}\text { Reduced vision } \\
(6 / 9 \text { to } 6 / 18) \\
N=5564\end{array}$ & $\begin{array}{l}\text { Visually impaired } \\
\text { (worse than 6/18) } \\
N=1723\end{array}$ & & \\
\hline Median binocular acuity (IQR range)** & $0.025(-0.025,0.1)$ & $0.3(0.225,0.35)$ & $0.625(0.525,0.8)$ & 167 & NA \\
\hline Mean age(SD) & $79.7(3.8)$ & $82.0(4.7)$ & $84.3(5.4)$ & 66 & $p<0.001$ \\
\hline 90 years and older (N\%) & $115(1.6)$ & $362(6.5)$ & $258(15.0)$ & 66 & $p<0.001$ \\
\hline Female (N\%) & $3997(56.2)$ & $3602(64.7)$ & $1220(70.8)$ & 0 & $\mathrm{p}<0.001$ \\
\hline Married (N\%) & $3419(49.2)$ & 2037(37.4) & $477(28.2)$ & 291 & $p=0.005$ \\
\hline Widowed (N\%) & $3148(45.3)$ & $3068(56.3)$ & $1074(63.4)$ & & \\
\hline Lives alone (N\%) & $3055(43.0)$ & $2827(50.8)$ & $936(54.3)$ & 0 & $p=0.293$ \\
\hline Home owner (N\%) & $4872(68.9)$ & $3342(60.4)$ & $929(54.8)$ & 97 & $p<0.001$ \\
\hline Sheltered accommodation (N\%) & $427(6.0)$ & $527(9.5)$ & $233(13.7)$ & & \\
\hline Financial difficulties (N\%) & $294(4.2)$ & $344(6.3)$ & $200(11.9)$ & 189 & $p<0.001$ \\
\hline $\begin{array}{l}\text { Looked after someone with a serious illness in last } \\
\text { year }(N \%)\end{array}$ & $963(13.8)$ & $727(\mid 3.3)$ & $215(12.8)$ & 255 & $p=0.891$ \\
\hline Death of loved one in last year (N\%) & $1168(16.6)$ & $922(16.8)$ & $317(18.7)$ & 157 & $p=0.117$ \\
\hline No relative/friend to call on/no help at night (N\%) & $436(6.5)$ & $346(6.8)$ & $100(6.6)$ & 1071 & $p=0.915$ \\
\hline Drinks above median alcohol consumption (N\%) & $1519(21.5)$ & $982(17.8)$ & $250(14.7)$ & 117 & $p<0.001$ \\
\hline Current smoker (N\%) & 679(9.6) & $561(10.1)$ & 204(11.9) & 22 & $p<0.001$ \\
\hline Mean body mass index (BMI)Mean (SD) & $26.2(4.1)$ & $26.0(4.3)$ & $25.3(4.5)$ & 1157 & $p=0.010$ \\
\hline Lightest fifth for BMI (N\%) & $1209(17.9)$ & $1009(20.0)$ & $410(28.5)$ & & $p=0.018$ \\
\hline Depression $(N \%)^{* *}$ & $378(5.4)$ & $493(9.1)$ & $219(13.2)$ & 381 & $p<0.001$ \\
\hline Diabetes (N\%) & $500(7.0)$ & $448(8.1)$ & $164(9.5)$ & 0 & $p<0.001$ \\
\hline \% Hearing impairment (N\%) & $1443(20.5)$ & $1495(27.2)$ & $613(36.1)$ & 156 & $p=0.002$ \\
\hline Reported major illness (N\%) & $1898(26.7)$ & $1750(31.5)$ & $585(34.0)$ & 20 & $\mathrm{P}<0.001$ \\
\hline Reported fair/poor health (N\%) & $837(11.8)$ & $988(17.9)$ & $394(23.1)$ & 88 & $p<0.001$ \\
\hline Unable to do 2-4 ADL (N\%) & $1002(14.2)$ & $1300(23.6)$ & $610(36.0)$ & 120 & $p<0.001$ \\
\hline Unable to do 5-8 ADL (N\%) & $307(4.4)$ & $626(11.4)$ & $394(23.2)$ & & \\
\hline 2 or more falls in last six months (N\%) & $408(5.8)$ & $543(9.8)$ & $221(13.0)$ & 53 & $p=0.005$ \\
\hline Not very/not at all active (N\%) & $1128(15.9)$ & $1456(26.3)$ & $640(37.7)$ & 87 & $\mathrm{p}<0.001$ \\
\hline MMSE I2-17 (N\%) & $173(2.5)$ & $252(4.6)$ & $225(13.3)$ & 138 & $p<0.001$ \\
\hline MMSE I8-23 (N\%) & $800(11.3)$ & $1051(19.1)$ & $542(32.1)$ & & \\
\hline
\end{tabular}

$\mathrm{IQR}=$ Interquartile range; $\mathrm{ADL}$ activities of daily living; MMSE mini mental state examination score.

* From multinomial logistic regression model. Dependent variable visual impairment (3 categories). Independent variables age, sex and row variable. All tests take into account the cluster design of the study.

**LogMAR score

potential explanatory social and co-morbidity factors eliminated this increased risk of hospital admission in visually impaired people. The rate ratio adjusting for all factors was 1.06 (95\% CI 0.94 to 1.20$)$. We repeated the analyses excluding variables potentially on the causal pathway. The rate ratio for hospital admission was 1.19 (95\% CI 1.06 to 1.34 ).

Table 3 shows the rate of hospital admission by cause of visual impairment. After adjustment for confounders there were no significant associations between cause of vision impairment and risk of admission.

The reason for hospital admission was specified for $87 \%$ of admissions, i.e. the speciality of the admission was recorded. $1.5 \%$ of admissions were classified as "accident and emergency". However, this figure probably represents admissions to small short stay wards found in some (but not all) casualty departments and is unlikely to reflect true visits to emergency departments. There was little association between visual impairment and risk of an "accident and emergency" admission (risk ratio controlling for all explanatory factors $0.73,95 \%$ CI 0.29 to 1.84 ).

There were 303 admissions recorded as "ophthalmology". Unsurprisingly people with visual impairment were more likely to be admitted for one or more ophthalmology admissions (risk ratio controlling for all explanatory factors $3.10,95 \%$ CI 2.24 to 4.29 ). Excluding these ophthalmology admissions did not change the results: the rate ratio adjusted for age and sex was 1.31 (95\% CI 1.17 to $1.46)$; the rate ratio adjusting for all factors was $1.04(95 \%$ 
Table 2: Hospital admission in visually impaired people aged 75 years and above

\begin{tabular}{|c|c|c|c|c|c|c|c|c|c|}
\hline \multirow[b]{2}{*}{$\begin{array}{l}\text { Binocular } \\
\text { presenting } \\
\text { vision with } \\
\text { usual glasses. }\end{array}$} & \multirow[b]{2}{*}{$\begin{array}{c}\text { Number of } \\
\text { people with } \\
\text { data on hospital } \\
\text { admission }\end{array}$} & \multirow[b]{2}{*}{ Admissions } & \multirow[b]{2}{*}{ Person-years } & \multicolumn{2}{|c|}{ Model I } & \multicolumn{2}{|c|}{ Model 2} & \multicolumn{2}{|c|}{ Model 3} \\
\hline & & & & Rate ratio & $95 \% \mathrm{Cl}$ & Rate ratio & $95 \% \mathrm{Cl}$ & Rate ratio & $95 \% \mathrm{Cl}$ \\
\hline $\begin{array}{l}\text { Good vision } \\
>6 / 9\end{array}$ & 7107 & 2302 & 13561.9 & I & & I & & I & \\
\hline $\begin{array}{l}\text { Reduced vision } \\
6 / 9 \text { to } 6 / 18\end{array}$ & 5564 & 2215 & 10329.3 & 1.22 & I.I2,I.34 & 1.10 & $1.00,1.21$ & 1.17 & $1.07,1.28$ \\
\hline $\begin{array}{l}\text { Visually } \\
\text { impaired } \\
<6 / 18\end{array}$ & 1723 & 737 & 3087.3 & 1.32 & I.19,1.47 & 1.06 & $0.94,1.20$ & 1.19 & $1.06,1.34$ \\
\hline Total & 14394 & 5254 & 26978.6 & $\begin{array}{c}\mathrm{N} \text { in model }= \\
\mid 4328\end{array}$ & & $\begin{array}{c}\mathrm{N} \text { in model }= \\
13494\end{array}$ & & $\begin{array}{c}N \text { in model }= \\
13940\end{array}$ & \\
\hline
\end{tabular}

$\mathrm{Cl}$ : confidence intervals MMSE: mini-mental state examination

53 practices; people with MMSE score of less than 12 were excluded; analyses take into account the cluster design of the study Model I: adjusted age and sex

Model 2: adjusted age, sex, housing tenure, financial difficulties, smoking, depression, diabetes, reported major illness, self-reported health, falls, ADL, self-reported activity, MMSE.

Model 3: adjusted age, sex, housing tenure, financial difficulties, smoking, diabetes, reported major illness, MMSE.

CI 0.92 to 1.18$)$; and the rate ratio adjusted for variables not potentially on the causal pathway was 1.17 (95\% CI 1.04 to 1.32$)$.

Visually impaired people had a longer median duration of hospital stay compared to people with good vision (12 days vs 8 days), $\mathrm{p}<0.001$ Wilcoxon rank sum test. After adjustment for explanatory factors not on the causal pathway visually impaired people stayed on average two extra days in hospital ( $\mathrm{p}=0.408)$.

\section{Discussion}

We found some evidence for an increased risk of hospital admission in visually impaired older people in the MRC trial over two years follow-up. Part of this increased risk was attributable to higher levels of co-morbidity and part attributable to factors which may be the consequence of reduced vision, such as reduced functional ability. However, in this large epidemiological study we cannot be sure for each individual exactly what caused the reported reduced functional ability - whether it was the visual impairment or some other factor such as arthritis or cardiovascular disease. Visual impairment and difficulty with activities of daily living were associated after controlling for all other factors which suggests that part of this reduced functional ability could be attributable to visual loss. However, analyses of the cause of visual impairment and hospital admission found no increased risk of hospital admission for causes of visual loss such as age-related macular degeneration. If the increased risk of hospital

Table 3: Association between cause of visual impairment and hospital admission

\begin{tabular}{|c|c|c|c|c|c|c|}
\hline & \multicolumn{2}{|c|}{ Model I } & \multicolumn{2}{|c|}{ Model 2} & \multicolumn{2}{|c|}{ Model 3} \\
\hline & Rate ratio & $95 \% \mathrm{Cl}$ & Rate ratio & $95 \% \mathrm{Cl}$ & Rate ratio & $95 \% \mathrm{Cl}$ \\
\hline Visual acuity $6 / 9$ or better & l & & I & & I & \\
\hline AMD & 1.32 & $0.98,1.79$ & 0.96 & $0.70,1.32$ & 1.13 & $0.83,1.54$ \\
\hline Cataract & 1.46 & $1.09,1.96$ & 1.20 & $0.86,1.67$ & 1.31 & $0.96,1.78$ \\
\hline Other causes & 1.42 & $1.02,1.97$ & I.I I & $0.74,1.67$ & 1.28 & $0.89,1.86$ \\
\hline Refractive error & $\mid .31$ & $1.04,1.66$ & 1.13 & $0.87,1.45$ & 1.20 & $0.94,1.54$ \\
\hline Cause unknown & 1.28 & $0.89,1.83$ & 1.14 & $0.78,1.68$ & 1.18 & $0.82,1.70$ \\
\hline
\end{tabular}

$\mathrm{Cl}$ : confidence intervals

49 practices; people with MMSE score of less than 12 were excluded; analyses take into account the cluster design of the study Model I: adjusted age and sex

Model 2: adjusted age, sex, housing tenure, financial difficulties, smoking, depression, diabetes, reported major illness, self-reported health, falls, ADL, self-reported activity, MMSE.

Model 3: adjusted age, sex, housing tenure, financial difficulties, smoking, diabetes, reported major illness, MMSE. 
admission was due to the visual impairment we might expect that conditions such as age-related macular degeneration which are associated with more severe visual impairment might show the effect more strongly. However this was not the case.

There are not many other studies on this topic. Jack et al measured the prevalence of visual impairment in 200 people aged 65 years and above admitted to one UK hospital with an acute medical illness[1]. They found that half of these people were visually impaired. Although this is a high prevalence of visual impairment it is difficult to interpret as the age structure of the hospital admissions is unlikely to reflect population age structure and the prevalence of visual impairment increases rapidly over the ages of 65 years and above[8,9]. Jacobs et al studied 839 people aged 77 in Israel and found that visual impairment was associated with an increased likelihood of attending for emergency care in men but not in women[2]. However, these analyses were not controlled for age or any other potentially confounding factors. Morse et al in New York State, USA, analysed routinely collected data on length of hospital stay[3]. Visual impairment was associated with an extra two days length of stay in hospital, after controlling for age, sex, payer source and other co-morbid conditions. We similarly found a non-significant increased length of stay in visually impaired older people of two days, after adjusting for explanatory factors not on the causal pathway.

Although these associations are interesting it cannot be assumed that screening for visual impairment in the community would necessarily lead to reductions in hospital admission and length of stay. Screening for visual impairment in this age-group does not appear to change the prevalence of visual impairment in this age-group[10]. The MRC trial which evaluated the benefit of screening for a wide range of health and social problems including vision did not find a benefit on rates of hospital admission[5].

\section{Conclusion}

The association between visual impairment and rate of hospital admission can be attributed to higher levels of co-morbidity and reduced functional ability among people with reduced vision. Visual impairment is likely to be an important contributor to reduced functional ability, but other factors will also be involved. This underlines the importance of taking a wider view of an older person rather than focussing on a single impairment or disability.

\section{Competing interests}

The authors declare that they have no competing interests.

\section{Authors' contributions}

JRE contributed to the conception and design of the study, collected data on cause of visual loss, did the analyses and drafted the paper. AF and LS contributed to the conception and design of the study, interpretation of the results and critical revision of the manuscript for important intellectual content. All authors read and approved the final manuscript.

\section{Acknowledgements}

The Medical Research Council Trial of the Assessment and Management of Older People in the Community was funded by the United Kingdom Medical Research Council, the Department of Health and the Scottish Office. Collection of data on causes of visual impairment and additional analyses were funded by the Thomas Pocklington Trust. LS is supported by a Senior Clinical Fellowship from the Wellcome Trust.

\section{References}

I. Jack Cl, Smith T, Neoh C, Lye M, McGalliard JN: Prevalence of low vision in elderly patients admitted to an acute geriatric unit in Liverpool: elderly people who fall are more likely to have low vision. Gerontology 1995, 41:280-285.

2. Jacobs JM, Hammerman-Rozenberg R, Maaravi $Y$, Cohen A, Stessman $J$ : The impact of visual impairment on health, function and mortality. Aging Clin Exp Res 2005, I 7:28I-286.

3. Morse AR, Yatzkan E, Berberich B, Arons RR: Acute Care Hospital Utilization by Patients With Visual Impairment. Arch Ophthalmol 1999, I I 7:943-949.

4. Fletcher AE, Jones DA, Bulpitt CJ, Tulloch AJ: The MRC trial of assessment and management of older people in the community: objectives, design and interventions [ISRCTN23494848]. BMC Health Services Research 2002, 2:2I.

5. Fletcher AE, Price GM, Ng ES, Stirling SL, Bulpitt CJ, Breeze E, et al: Population-based multidimensional assessment of older people in UK general practice: a cluster-randomised factorial trial. The Lancet 2004, 364:1667-1677.

6. McGraw PV, Winn B: Glasgow Acuity Cards: a new test for the measurement of letter acuity in children. Ophthalmol Physiol Opt 1993, 13:400-404.

7. Evans JR, Fletcher AE, Wormald RPL: Causes of visual impairment in people aged 75 years and above in Britain: an add-on study to the MRC Trial of assessment and management of older people in the community. British Journal of Ophthalmology 2002, 88:365-370.

8. Pols JC van der, Bates CJ, McGraw PV, Thompson JR, Reacher M, Prentice $A$, et al: Visual acuity measurements in a national sample of British elderly people. $\mathrm{Br} J$ Ophthalmol 2000, 84: $165-170$.

9. Evans JR, Fletcher AE, Wormald RPL, Siu-Woon $\mathrm{Ng}$ E, Stirling $\mathrm{S}$, Smeeth L, et al.: Prevalence of visual impairment in people aged 75 years and older in Britain: results from the MRC trial of assessment and management of older people in the community. Br J Ophthalmol 2002, 86:795-800.

10. Smeeth L, lliffe S: Community screening for visual impairment in the elderly. Cochrane Database Syst Rev 2006, I 9(3):CD00 054.

\section{Pre-publication history}

The pre-publication history for this paper can be accessed here:

http://www.biomedcentral.com/1471-2415/8/16/prepub 